\title{
Formaldehyde determination in seawater. Preliminary application to coastal samples at Terra Nova Bay (Antarctica)
}

\author{
O. Largiuni, ${ }^{a}{ }^{a}$ S. Becagli, ${ }^{b}$ M. Innocenti, ${ }^{b}$ A. M. Stortini, ${ }^{c}{ }^{2}$. Traversi ${ }^{b}$ and R. Udisti ${ }^{b}$ \\ ${ }^{a}$ Centre for Geotechnologies, University of Siena, V. Vetri Vecchi 34, I-52027 San Giovanni \\ Valdarno (AR), Arezzo, Italy.E-mail: ombretta.largiuni@unisi.it; Fax: +39 55 9119439; \\ Tel: +3955 9119464 \\ ${ }^{\boldsymbol{b}}$ Department of Chemistry, University of Florence-Scientific Pole, Via della Lastruccia 3, \\ I-50019 Sesto Fiorentino (FI), Italy \\ ${ }^{c}$ Department of Environmental Science, University Ca' Foscari, Calle Larga Santa Marta 2137, \\ I-30123 Venice, Italy
}

Received 23rd May 2005, Accepted 8th September 2005

First published as an Advance Article on the web 27th September 2005

A sensitive spectrofluorimetric-FIA (flow injection analysis) method for formaldehyde (HCHO) determination was improved with the aim of analysing seawater samples. The fluorescence emission versus $\mathrm{HCHO}$ concentration shows a linear pattern from sub $\mu \mathrm{g} \mathrm{L}^{-1}$ to about $1000 \mu \mathrm{g} \mathrm{L}^{-1}$. The reproducibility at $15 \mathrm{ppb}$ level is about $2 \%$. Interferences from other aldehydes were checked; only glyoxal shows a significative interference, but only when its concentration is about 6000 times higher than that of formaldehyde. Superficial (microlayer, just sub-pack or sea-ice free sea surface) and deep (along the water column, sub-pack or in sea-ice free areas) seawater samples were collected near the coast at Terra Nova Bay (Ross Sea, Antarctica) during the 1998/1999 and 2001/2002 Italian Antarctic Expedition. We report here the preliminary results of the spectrofluorimetric-FIA determination of the HCHO content. The mean seawater superficial formaldehyde concentration was $15 \mu \mathrm{g} \mathrm{L}^{-1}$; the concentration along the water column ranged between 4.5 to over $40 \mu \mathrm{g} \mathrm{L}^{-1}\left(20 \mu \mathrm{g} \mathrm{L}^{-1}\right.$ mean concentration), usually with a maximum value for the $30 \mathrm{~m}$ depth, corresponding to a fluorescence maximum. The sampling was repeated 7 times in the austral summer in order to evaluate seasonal changes in the formaldehyde concentration/seawater depth profiles. The results show changes in the formaldehyde concentration at different depths.

\section{Introduction}

Formaldehyde is a key reactive intermediate in the methane oxidation chain. This compound can be directly emitted to the atmosphere by anthropogenic (automobile exhaust gases and industrial emissions) and natural sources, ${ }^{1}$ but it can also be formed in the atmosphere as an intermediate product of the photo-oxidation of methane and other hydrocarbons emitted by natural and anthropogenic sources. ${ }^{2}$ It plays an important role (as a free radical source) in the reactions occurring in the troposphere. $\mathrm{HCHO}$ inhibits $\mathrm{S}$ (Iv) oxidation to $\mathrm{H}_{2} \mathrm{SO}_{4}$ and it is a precursor of $\mathrm{HCOOH} ;, 3$ moreover it influences the oxidizing capacity of the troposphere through interactions of $\mathrm{H}_{2} \mathrm{O}_{2}$ with $\mathrm{OH}^{\bullet}$ and $\mathrm{HO}_{2}{ }^{\cdot}$ radicals. ${ }^{5}$ Because of its behaviour in atmospheric processes, accurate measurements of $\mathrm{HCHO}$ appear to be essential for understanding the atmospheric cycles of a large range of organic and inorganic compounds.

Oceans are critical to the dynamics of the earth system due to their role in controlling global energy and material budgets, and hence in regulating the global climate. Within the earth system, the oceans are intimately linked with the atmosphere and the continental areas, and so they cannot be considered separately when addressing questions of global change. ${ }^{6}$

Low-molecular-weight (LMW) carbonyl compounds are of special interest in the oceanic organic compounds cycles. Photochemical oxidation processes, such as photodegradation of humic substances and other UV-absorbing organic compounds, constitute a major source of LMW carbonyl compounds in subsurface water. ${ }^{7,8}$
Surface film present at the air-sea interface (marine microlayer, 1 to $1000 \mu \mathrm{m}$ thick) is the crossing area between the bulk water (liquid phase) and atmosphere (gas phase), as well as an environmental compartment with own properties and structural composition. ${ }^{9,10}$ It is exposed to the most intense solar radiation compared to the rest of the water column, therefore many photochemical reactions may occur in the microlayer, such as photoproduction of LMW carbonyl compounds. Since the microorganism population is enriched in the microlayer, microbial activity could strongly influence the concentrations of carbonyl compounds in the uppermost seawater. However, additional sources and sinks must be considered. Exchange with the atmosphere may be a source for highly soluble compounds, such as formaldehyde. ${ }^{8}$

Coastal marine polar regions are characterised by a sea-ice seasonal cycle: in the spring-summer time, the well mixed seawater becomes superficially stratified by thermal heating and freshwater input from sea-ice melting. The low density surface layer constitutes a preferential site for the phytoplanktonic growth during the austral spring and summer. Satellite images have shown relevant phytoplankton blooms in the Ross Sea, one of the major shelf seas around Antarctica. ${ }^{11}$ The intense seasonal phytoplankton blooms produce seasonal variations in surface productivity and biogenic matter concentration throughout the water column. ${ }^{12}$

The study of causes and seasonal changes in the community structure of the large bloom occurring in early summer in the Ross Sea is relevant in order to identify the factors and processes which regulate the magnitude and variability of 
primary productivity and the fate of biogenic matter, to determine the response of the Southern Ocean to natural climate perturbations and to predict the response of the Southern Ocean to climatic change. ${ }^{13}$

In this work a sensitive spectrofluorimetric FIA method for formaldehyde determination was tested for its application to the analysis of seawater samples. The method was applied to samples collected at different depths in the Terra Nova Bay (Ross Sea, Antarctica), before and after the sea-ice melting. Because of the poor knowledge of $\mathrm{HCHO}$ concentrations in superficial and deep seawater and the lack of measurements of this compound in the Antarctic coastal areas, the preliminary results reported here may contribute to the understanding of the behaviour of carbonyl and other organic compounds in coastal Antarctic waters and their relationships with the sea-ice cycle.

\section{Experimental}

The analytical method for $\mathrm{HCHO}$ determination is based on the Hantzsch reaction between $\mathrm{HCHO}$ and acetylacetone, acetic acid and ammonium acetate to form diacetyldihydrolutidine (DDL); a non-ionic surfactant (Triton X-100) was used to enhance the fluorescence signal by decreasing the quenching effects. $^{14}$

The samples were injected, via a 4-way Teflon Rheodyne Type-50 injection valve with a loop of $250 \mu \mathrm{L}$, into a flow of

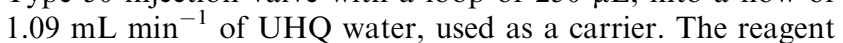
solution (acetic acid $0.177 \mathrm{M}$, acetylacetone $0.145 \mathrm{M}$ and ammonium acetate $2 \mathrm{M}$ ) was added, with a flow of $0.19 \mathrm{~mL}$ $\mathrm{min}^{-1}$ to the liquid line, and the reaction coil $(0.5 \mathrm{~mm}$ id, 200 $\mathrm{cm}$ long) was warmed up to $75^{\circ} \mathrm{C}$ in an in-line dry block heater (Thermobloc Falk 3372). After the reaction, $0.19 \mathrm{~mL} \mathrm{~min}^{-1}$ of Triton X-100 at $10 \%(\mathrm{w} / \mathrm{w})$ was added to protect the fluorescence. A Shimadzu RF-551 spectrofluorimeter with a $150 \mathrm{~W}$ xenon lamp was used as the detector; the excitation and emission wavelengths were, respectively, $\lambda_{\mathrm{ex}}=410 \mathrm{~nm}$ and $\lambda_{\mathrm{em}}=502 \mathrm{~nm}$. Data acquisition and elaboration were performed by a CSW version 1.7 Date Apex Ltd. integration program.

All solutions were prepared with reagent grade chemicals (Merck) and UHQ water (resistivity $>18 \mathrm{M} \Omega$ ), obtained from a Millipore-Milli $Q$ system and continuously recycled by an Elga UHQ apparatus.

Reagents were prepared every day. Fresh formaldehyde standards were prepared by serial dilution from a stock standard of $1000 \mathrm{ppm}$ obtained by dilution and titration of a $37 \%$ commercial solution.

A detailed description of the analytical apparatus and of the method performance is reported by Largiuni et al. ${ }^{14}$

\section{Dynamic range}

The concentration/fluorescence emission (arbitrary units, AU) calibration curves, obtained using the standard addition method on real seawater samples, demonstrated a good linearity $(R>0.9999)$ throughout the concentration range from $4.6 \mu \mathrm{g}$ $\mathrm{L}^{-1}$ (lowest concentration measured on the Terra Nova Bay samples: B10-6, superficial seawater) to about $1000 \mu \mathrm{g} \mathrm{L}^{-1}$.

Figs. 1a and $1 \mathrm{~b}$ show the linear relationship between $\mathrm{HCHO}$ concentration and detector response at two different acquisition settings; the calibration graphs were obtained performing standard solution additions to seawater samples. The first setting ( $1 \mathrm{~V}$ full scale) shows a good linearity up to $200 \mu \mathrm{g}$ $\mathrm{L}^{-1}$, the second one ( $5 \mathrm{~V}$ full scale) shows that concentrations as high as $1000 \mu \mathrm{g} \mathrm{L}^{-1}$ can be fully determined.
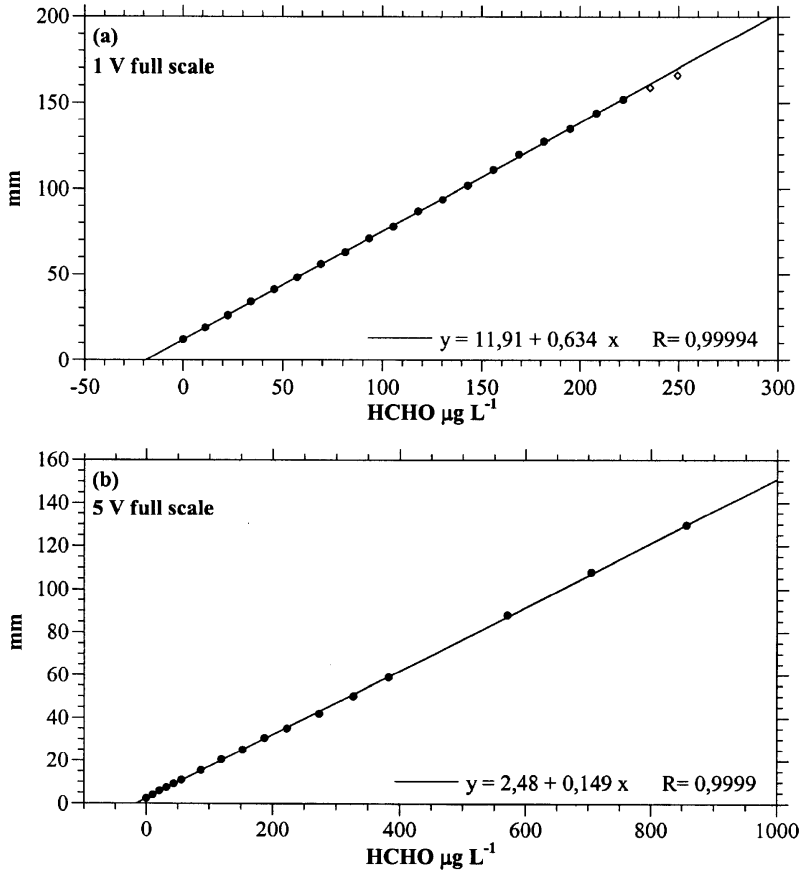

Fig. 1 Linear calibration graphs obtained with the standard addition method at two different acquisition settings: (a) $1 \mathrm{~V}$ full scale and (b) $5 \mathrm{~V}$ full scale.

\section{Reproducibility and detection limit}

The standard deviation estimation (SD) of the analysis of 13 replicates of a sample containing $16 \mu \mathrm{g} \mathrm{L}^{-1}$ of $\mathrm{HCHO}$ was 0.35 $\mu \mathrm{g} \mathrm{L}^{-1}$ (relative standard deviation $\mathrm{RSD}=2.2 \%$ ). At this concentration level, the detection limit, calculated as the concentration corresponding to twice the standard deviation, was $0.7 \mu \mathrm{g} \mathrm{L}^{-1}$.

Fig. 2 shows the values related to the 13 replicates of the 16 $\mu \mathrm{g} \mathrm{L}^{-1}$ sample; the mean concentration and standard deviation are also reported.

Fig. 3 shows the acquisition plot of the fluorescence response $(\mathrm{mV}) v s$. time $(\mathrm{min})$ for a seawater sample; the linear regression is also plotted. A $\mathrm{HCHO}$ solution of $1.5 \mathrm{mg} \mathrm{L}^{-1}$ was prepared from the $1000 \mathrm{mg} \mathrm{L}^{-1}$ titrated solution (see above) and $50 \mu \mathrm{L}$ of this was successively added in the bottle with the sample after their analysis. The fluorescence signal was registered again; this was repeated three times. Peak 1 is related to the HCHO measured in the seawater sample, whereas peaks 2, 3 and 4 show the response to successive standard additions.

\section{Interferences}

The interference of low molecular weight aldehydes and other organic compounds was checked and was found negligible even

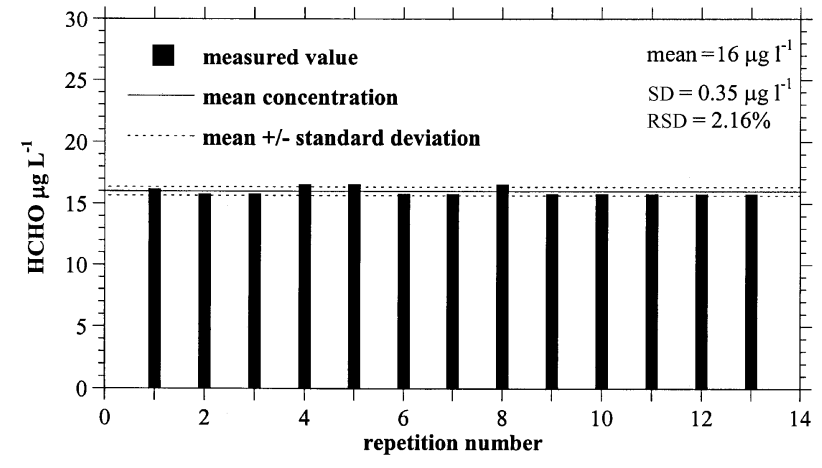

Fig. 2 Reproducibility on a seawater sample of $16 \mu \mathrm{g} \mathrm{L} \mathrm{L}^{-1}$ $(\mathrm{SD}=$ standard deviation, $\mathrm{RSD}=$ relative standard deviation $)$. 

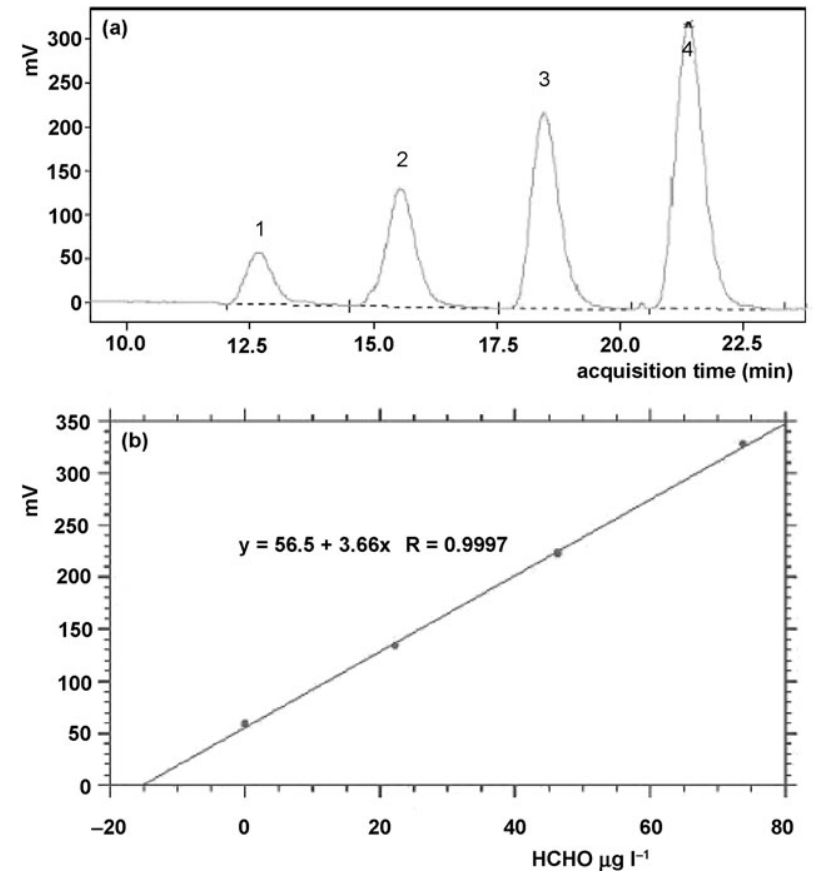

Fig. 3 Sample analysis with the internal standard method. Fig. 3a shows the acquisition graph and Fig. $3 \mathrm{~b}$ the linear calibration graph.

when interfering substances were added in a very large concentration excess, ca. 1000 times, with respect to the $\mathrm{HCHO}$ levels. Table 1 shows the slope of the linear calibrations (sensitivities) obtained adding standard solutions of $\mathrm{HCHO}$ and several other compounds to a seawater sample (standard addition method). In the same table, the method selectivity, calculated as the ratio between the slope of HCHO linear calibration $v s$. the slope of the interfering species, was reported. Only glyoxal shows a significant interference, but it can affect the HCHO measurements when its concentration is about 6000 times higher than that of $\mathrm{HCHO}$. No interference occurred when benzaldehyde, methanol, ethanol and acetone were added at concentrations as high as $600 \mathrm{mg} \mathrm{L}^{-1}$.

\section{Sampling}

Microlayer and sub-surface samples as well as sub-pack bulk seawater were collected in the Gerlache Inlet area (Terra Nova Bay, Ross Sea, Antarctica) during the 1998/1999 and 2001/ 2002 Italian Antarctic Campaign respectively, in the framework of the Italian National Program for Antarctic Research (PNRA). Fig. 4 shows the sampling sites in the Gerlache Inlet.

The samples were collected and stored in polyethylene bottles $(250 \mathrm{~mL})$. The bottles were previously cleaned with a

Table 1 Interfering species on formaldehyde determination

\begin{tabular}{llc}
\hline Compound & Slope of linear calibration & Selectivity \\
\hline Formaldehyde & 1.4 & 1 \\
Glyoxal & 0.00025194 & 5557 \\
Glutaraldehyde & 0.00005154 & 27163 \\
Ethanal & 0.00004041 & 34645 \\
Propanal & 0.00000374 & 374332 \\
Formic acid & 0.00000128 & 1093750 \\
Acetic acid & 0.00000105 & 1333333 \\
Benzaldehyde & & No interference \\
Ethanol & & No interference \\
Methanol & & No interference \\
Acetone & & No interference \\
& & \\
a & & \\
Note: at $600 \mathrm{mg} \mathrm{L}^{-1}$ concentration level of potentially interfering
\end{tabular}

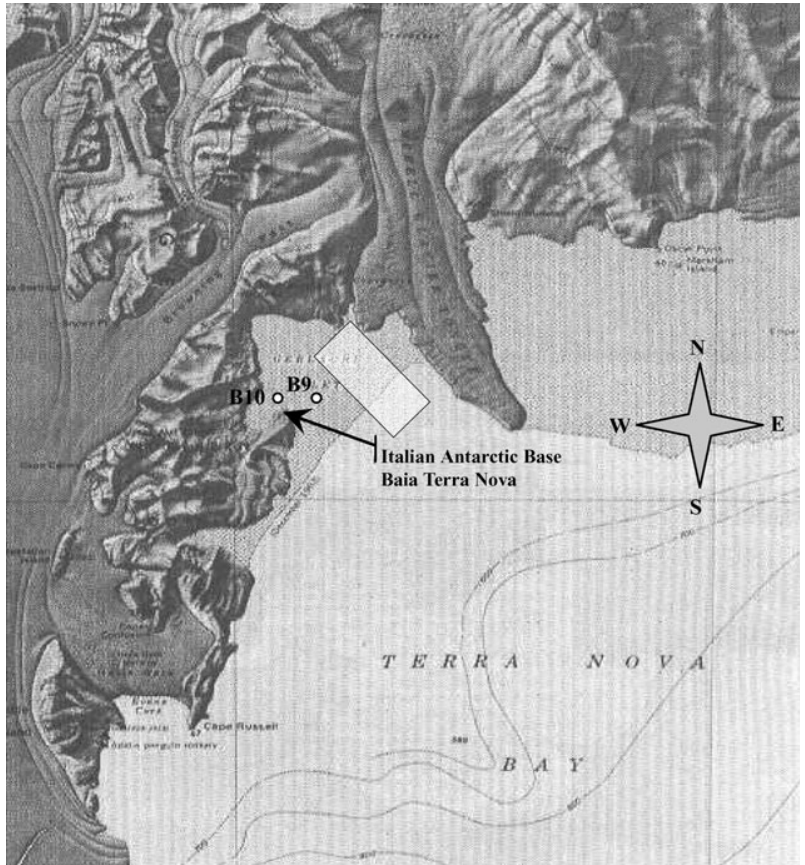

Fig. 4 Map of Terra Nova Bay (Victoria Land, Antarctica). The light grey square reports the area for sea surface microlayer and for subsurface water, and sampling stations B9 and B10 are also reported. The sampling sites (B9 and B10) and the sampling area for surface microlayer and sub-surface water are enhanced in the Gerlache Inlet. Italian summer station is also indicated on the map (Lat. $74^{\circ} 41^{\prime} 42^{\prime \prime} \mathrm{S}$-Long. $\left.164^{\circ} 07^{\prime} 23^{\prime \prime} \mathrm{E}\right)$.

solution of non-ionic surfactant (Extran) for $24 \mathrm{~h}$, then they were rinsed with tap water and rinsed out many times with MilliQ water. Successively, a $2 \%$ suprapur $\mathrm{HCl}$ solution was added and the filled bottles were stored for several days. Then the bottles were washed with milliQ water and the inner part was cleaned with stream generated from MilliQ water for 10 min. Finally, last washing with milliQ water was performed. Bottles were dried in a 100-class laminar flow bench.

Sea surface microlayer (SML) and sub-surface sea water (SSW) samples were collected in sea-ice free areas by using an electrically powered catamaran named Multi-Use Microlayer Sampler (MUMS). ${ }^{15,16}$ The MUMS movements were radiocontrolled from a motorboat sailing about $100 \mathrm{~m}$ down-wind to avoid sample contamination. The MUMS was built as described by Harvey. ${ }^{17}$ The microlayer sampling was carried out by a Pyrex glass rotating drum $(315 \mathrm{~mm}$ diameter, $500 \mathrm{~mm}$ length, $7 \mathrm{rpm}$ speed). The material adsorbed on the drum surface was removed by a Mylar scraper. The collected fraction was automatically sent into pre-cleaned polyethylene bottles by a Teflon membrane pump. The rotating drum, as well as the collector apparatus, were washed with seawater for $10 \mathrm{~min}$ before sampling. The flow of the collected fractions was switched in the bottles or discharged to the sea by a Teflon solenoid three-way valve. All sampling apparatus (with the exception of the glass drum) was built using Teflon.

Sub-surface water was collected by immersing the end of the Teflon sampling tube to a depth of about $0.5 \mathrm{~m}$.

SML and SSW samples were collected in calm sea conditions (wind speed <5-6 knots) in polyethylene bottles and stored at $-30{ }^{\circ} \mathrm{C}$ until the analysis.

Table 2 lists the SML and SSW sampling characteristics and information about wind speed and air temperature during the collection.

Bulk seawater samples were collected during the 2001/2002 campaign at different depths along the water column by using pre-cleaned stainless steel Go-Flo-type bottles. After collecting, the samples were stored in polyethylene bottles at $-30{ }^{\circ} \mathrm{C}$ until the analysis. 
Table 2 Data sampling for sea surface microlayer (SML) and subsurface water (SSW) collected during 1998/1999 Italian Antarctic Campaign. Water temperature during the campaign went from about $0.7{ }^{\circ} \mathrm{C}$ to $-1.7^{\circ} \mathrm{C}$

\begin{tabular}{lllll}
\hline & $\begin{array}{l}\text { Sample } \\
\text { type }\end{array}$ & $\begin{array}{l}\text { Sampling data } \\
(\mathrm{mm} / \mathrm{dd} / \mathrm{yy})\end{array}$ & $\begin{array}{l}\text { Wind speed } / \\
\text { knots }\end{array}$ & $\begin{array}{l}\text { Air } \\
\text { temperature } /{ }^{\circ} \mathrm{C}\end{array}$ \\
\hline M1 & SML & $01 / 23 / 99$ & $1-2$ & $0 /+1$ \\
M2 & SML & $01 / 30 / 99$ & $1-2$ & $0 /+2$ \\
M3 & SML & $02 / 03 / 99$ & $7-8^{a}$ & $0 /-1$ \\
M4 & SML & $02 / 10 / 99$ & $7-8^{a}$ & $0 /-2$ \\
& & & & \\
S1 & SSW & $01 / 23 / 99$ & $1-7$ & $0 /-2$ \\
S2 & SSW & $01 / 30 / 99$ & $7-8^{a}$ & $0 /-2$ \\
S3 & SSW & $02 / 03 / 99$ & $1-2$ & $-2 /-4$ \\
S4 & SSW & $02 / 10 / 99$ & $1-2$ & $-2 /-4$ \\
${ }^{a}$ Note: & sudden wind gust. & & \\
\hline
\end{tabular}

During the sampling, a CTD ME multiparametric probe (mod. KMS088) recorded the temperature, salinity and fluorescence of the seawater layers with a resolution of $1 \mathrm{~m}$.

Table 3 shows the basic sampling information.

\section{Results and discussion}

Table 4 shows the HCHO concentrations measured in subsurface water (SSW) and sea surface micro-layer (SML) samples. Fig. 5 shows the $\mathrm{HCHO}$ concentration measured in all the seawater samples collected in the 2001/2002 campaign and plots their concentration/depth profiles.

To date, only few measurements of $\mathrm{HCHO}$ in surface seawater have been reported, ${ }^{7,8}$ suggesting a net flux of $\mathrm{HCHO}$ from the atmosphere to the ocean surface. Although the ocean

Table 3 Data sampling for sub-pack bulk water collected during 2001/2002 Italian Antarctic Campaign

\begin{tabular}{|c|c|c|c|}
\hline Sampling & Sample & $\begin{array}{l}\text { Sampling date } \\
(\mathrm{mm} / \mathrm{dd} / \mathrm{yy})\end{array}$ & Depth/m \\
\hline 1) & $\begin{array}{ll}\text { B9-1 } & \text { SW }-1 \\
\text { B9-1 } & \text { SW }-25 \\
\text { B9-1 } & \text { SW }-50\end{array}$ & $11 / 09 / 01$ & $\begin{array}{r}-1 \\
-25 \\
-50\end{array}$ \\
\hline 2) & $\begin{array}{l}\text { B9-2 SW }-1 \\
\text { B9-2 SW }-25 \\
\text { B9-2 SW }-50\end{array}$ & $11 / 27 / 01$ & $\begin{array}{r}-1 \\
-25 \\
-50\end{array}$ \\
\hline 3) & $\begin{array}{l}\text { B10-1 SW - } 14 \\
\text { B10-1 SW }-30 \\
\text { B10-1 } \\
\text { SW }-50\end{array}$ & $12 / 10 / 01$ & $\begin{array}{l}-14 \\
-30 \\
-50\end{array}$ \\
\hline 4) & $\begin{array}{l}\text { B10-2 SW - } 14 \\
\text { B10-2 SW -30 } \\
\text { B10-2 SW -50 }\end{array}$ & $12 / 22 / 01$ & $\begin{array}{l}-14 \\
-30 \\
-50\end{array}$ \\
\hline 5) & $\begin{array}{l}\text { B10-4 SW - } \\
\text { B10-4 SW - } 10 \\
\text { B10-4 SW -30 } \\
\text { B10-4 SW -50 }\end{array}$ & $01 / 16 / 02$ & $\begin{array}{r}-1 \\
-10 \\
-30 \\
-50\end{array}$ \\
\hline 6) & $\begin{array}{l}\text { B10-5 SW }-1 \\
\text { B10-5 SW }-10 \\
\text { B10-5 SW }-30 \\
\text { B10-5 SW }-50\end{array}$ & $01 / 26 / 02$ & $\begin{array}{r}-1 \\
-10 \\
-30 \\
-50\end{array}$ \\
\hline 7) & $\begin{array}{l}\text { B10-6 SW - } \\
\text { B10-6 SW - } 10 \\
\text { B10-6 SW -30 }\end{array}$ & $02 / 02 / 02$ & $\begin{array}{r}-1 \\
-10 \\
-30\end{array}$ \\
\hline
\end{tabular}

Table 4 Formaldehyde concentration in SML (sea surface microlayer) and SSW (sub-surface water) samples collected during 1998/1999 Italian Antarctic Campaign

\begin{tabular}{llll}
\hline $\begin{array}{l}\text { Sampling data } \\
(\mathrm{mm} / \mathrm{dd} / \mathrm{yy})\end{array}$ & $\begin{array}{l}\text { SML HCHO/ } \\
\mu \mathrm{g} \mathrm{L}^{-1}\end{array}$ & $\begin{array}{l}\text { SSW HCHO/ } \\
\mu \mathrm{g} \mathrm{L}^{-1}\end{array}$ & E.F. $^{a}$ \\
\hline $01 / 23 / 99$ & 13.9 & 10.8 & 1.29 \\
$01 / 30 / 99$ & 23.3 & 24.1 & 0.97 \\
$02 / 03 / 99$ & 10.9 & 6.6 & 1.66 \\
$02 / 10 / 99$ & 13.7 & 15.4 & 0.89 \\
Mean value & 15.5 & 14.2 & 1.20 \\
${ }^{a}$ E.F. = enrichment factor SML/SSW. & & \\
\hline
\end{tabular}

is usually considered as a sink for atmospheric $\mathrm{HCHO}$, it cannot be excluded that marine areas characterized by high biogenic activity constitute a source of emission of $\mathrm{HCHO}$ into the atmosphere. ${ }^{18}$ Indeed, laboratory experiments carried out on seawater microlayer show HCHO production by photooxidation of dissolved organic matter. Results from laboratory studies indicate that low molecular weight (LMW) carbonyl compounds, especially formaldehyde, acetaldehyde, acetone and glyoxal, can be formed in seawater by photochemical processes. $^{7,8}$ Once formed, these compounds appear to be readily consumed by biota. These results suggest that concentrations of LMW carbonyl compounds should undergo diurnal variations in the sea photolytic layers. ${ }^{8}$ Surface waters off the west coast of Florida show little diurnal fluctuation in formaldehyde content, ranging from 0.45 to $1.5 \mu \mathrm{g} \mathrm{L}^{-1}$. ${ }^{7}$ To our knowledge, to date only Eberhardt and Sieburth ${ }^{19}$ have reported $\mathrm{HCHO}$ measurements on deep seawater samples, collected in the Peru upwelling region $\left(10^{\circ} \mathrm{S}, 79^{\circ} \mathrm{W}\right)$. In this area, the depth profile of aldehyde concentrations peak in the photic zone $(80 \mathrm{~m})$, with concentration values ranging from 18 to $264 \mu \mathrm{g} \mathrm{L}^{-1}$.

By considering a uniform $\mathrm{HCHO}$ distribution of $0.015 \mu \mathrm{g}$ $\mathrm{L}^{-1}$ in the seawater, at least in the thermocline, the depth of which varies from 20 to $50 \mathrm{~m}$ depending on season, the total concentration of $\mathrm{HCHO}$ in seawater can range between 10 and $25 \mu \mathrm{mol} \mathrm{m}{ }^{-2}{ }^{20}$

The analysis of pack-ice, immediately underlying sea-water and various-depth sea-water samples, collected at Terra Nova Bay during the 1988/1989 and 1990/1991 Italian Antarctic Expeditions, revealed the presence of relatively large concentrations of organic compounds. ${ }^{21,22}$ The results showed that the pack-ice is enriched in both biogenic and anthropogenic organic compounds with respect to the immediately underlying sea-water. On the contrary, no appreciable differences in the load and composition of organic compounds were found in seawater samples collected under the pack or offshore (Ross Sea). Aldehydes showed pack-ice concentrations ranging from 78 to $181 \mathrm{ng} \mathrm{L}^{-1}$. These data confirm previous results reporting a net flux of organic compounds from seawater to the pack ice during the sea-ice formation and growth. This pattern could be explained by the fact that the pack forms from the surface down and incorporates all the organic compounds present at the marine surface micro-layer which is, as known, more enriched in organic compounds than the bulk seawaters.

\section{Microlayer}

During the 1998/1999 Italian Antarctic campaign, only four microlayer samplings were carried out. Indeed, a reliable microlayer sampling is possible only when the sea is completely calm and the wind is practically absent; therefore, the sampling planning is strictly related to the weather conditions at the sampling site.

The samples were melted in a laminar flow bench just before the analysis. 


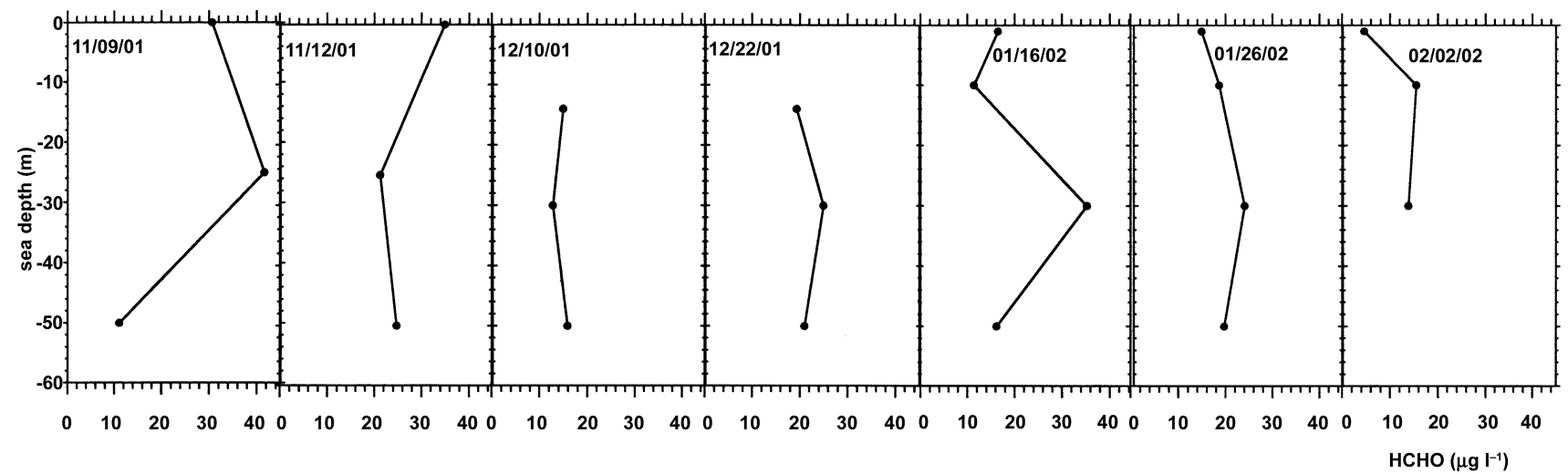

Fig. $5 \mathrm{HCHO}$ concentration/depth profiles in the water column.

Table 4 shows the HCHO concentrations in the microlayer and in the sub-surface water samples; the enrichment factors (E.F.), calculated as microlayer/sub-surface concentration ratios, are also shown. Unexpectedly, the E.F.s were close to 1, ranging from 0.89 to 1.66 , and the mean formaldehyde concentrations in the microlayer and in the superficial water were 14.2 and $15.5 \mu \mathrm{g} \mathrm{L}^{-1}$, respectively.

Very few HCHO measurements in the microlayer have been reported in the literature. Zhou and Mopper ${ }^{8}$ collected coastal (in the Hatchet Bay, Eleuthera Island, Bahamas and in the Biscayne Bay, Miami, Florida) and oceanic (in the South Sargasso Sea, about $100 \mathrm{~km}$ east of the Bahamas) surface microlayer samples, by using a stainless steel screen to remove thin slices of water from the sea surface (a surface layer thickness of about $150 \mu \mathrm{m}$ was sampled), along with subsurface bulk seawater. Samples were analysed for low-molecular-weight (LMW) carbonyl compounds, including formaldehyde. In oceanic samples, formaldehyde concentration ranges were from $0.114 \mu \mathrm{g} \mathrm{L}^{-1}$ in sub-surface seawater to $1.05 \mu \mathrm{g} \mathrm{L}^{-1}$ in the surface microlayer. Coastal water values were significantly higher: $0.45-1.26 \mu \mathrm{g} \mathrm{L}^{-1}$ in bulk seawater and $1.35-5.16 \mu \mathrm{g} \mathrm{L}^{-1}$ in the microlayer, respectively. The enrichment factors, ranging from 1.2 to 21 , were found to be higher in afternoon samples with respect to samples collected in the early morning and increased from coastal to open ocean waters. The exposure of the sea surface to sunlight resulted in the higher yields of these compounds in the surface microlayer than in the bulk seawater, suggesting that the higher photoproduction rate of LMW carbonyl compounds in the surface microlayer accounts for the majority of the observed enrichment in these samples.

Contrary to the observations of Zhou and Mopper, ${ }^{8}$ the Terra Nova Bay samples do not show E.F.s significantly different from 1.0, although the samples were collected during the austral summer, with an all day solar irradiation. On the other hand, the microlayer and bulk seawater HCHO concentration values were very much higher than those measured by Zhou and Mopper, ${ }^{8}$ indicating higher biogenic productivity and, maybe, the higher photoproduction rate of carbonylic substances in the seawater superficial layers collected at Terra Nova Bay.

$\mathrm{HCHO}$ enrichment in the marine microlayer depends on bulk-to-surface movements, air-to-seawater adsorption and scavenging processes, and $\mathrm{HCHO}$ microlayer residence times, rather than on the photochemical production rate.

The particular seawater stratification occurring in Antarctic coastal sites, with a superficial low-density layer coming from sea-ice melting, could affect the bulk-surface interchanges, making the microlayer enrichment lower.

The residence times of the LMW carbonyl compounds in the microlayer were estimated to be of the order of tens of seconds to minutes, using a modification of the two-layer model..$^{23}$ However, to obtain a significant microlayer enrichment, the residence time should be higher (about $1 \mathrm{~h}$ ). This prolonged residence time may be due to organic enrichment in the surface microlayer ("organic film") that slows down the molecular transfer of carbonyl compounds into and out of the microlayer. $^{8}$

DOM (dissolved organic matter) enrichment in the surface microlayer has been reported to be variable, from slightly less than 1 to about 8 . Since the photoproduction rates of carbonyl compounds are proportional to the concentration of UVabsorbing DOM content in the water sample, the large variation in their enrichment ratios can be explained in terms of large variations in the enrichment factor of UV-absorbing DOM in the microlayer, with respect to the bulk seawater content. ${ }^{8}$

A higher $\mathrm{HCHO}$ surface concentration could be caused by higher atmosphere-to-seawater apparent partition coefficients, as a result of its physical and chemical interactions with the organic matrix in the surface microlayer. ${ }^{8}$ Indeed, because the air-to-sea apparent partition coefficient is inversely proportional to the temperature, the low temperatures of coastal Antarctic sites such as Terra Nova Bay should fix higher aqueous formaldehyde concentrations. In any case, the $\mathrm{HCHO}$ residence time in the microlayer via air-sea exchange was evaluated to be about $1.2 \mathrm{~min}$ (Zhou and Mopper, 1997). This time is likely to be too short to allow a significant enrichment in the Terra Nova Bay microlayer, justifying the low values here reported.

\section{Water column}

The 23 samples collected at different depths (generally $1 \mathrm{~m}$, 10-15 $\mathrm{m}, 25-30 \mathrm{~m}, 50-60 \mathrm{~m}$ ) in the $\mathrm{B}_{9}$ and $\mathrm{B}_{10}$ stations (Gerlache Inlet-Terra Nova Bay, Western Ross Sea), during the 2001/2002 field campaign (November 2001 to February 2002), were analysed to evaluate formaldehyde profiles throughout the water column.

Formaldehyde concentrations ranged from 4.6 to $41.6 \mu \mathrm{g}$ $\mathrm{L}^{-1}$, with median and mean concentrations of 20.8 and $18.6 \mu \mathrm{g}$ $\mathrm{L}^{-1}$, respectively. These high values fully confirm the 1998/99 microlayer and sub-surface seawater concentrations.

Fig. 5 shows the concentration/depth profiles at the different sampling sites. All the samples was replicated three times. The reproducibility is about $2 \%$ and it is represented by the dimension of points in the graphs.

The concentration/depth trends are similar (with few exceptions), showing a maximum value at about $30 \mathrm{~m}$ depth, corresponding to the fluorescence maximum (Final ReportSummer Antarctic Campaign 2001-2002-XVII Expedition, Italian National Program for Antarctic Research (PNRA)). This evidence agrees with the Doval et al. ${ }^{24}$ observation concerning analysing seawater samples collected during the FRUELA '95 cruise in the Bransfield and Gerlache Straits. They showed that below the upper mixed layer (UML), whose 
border was located at $25-50 \mathrm{~m}$ depth, the dissolved organic carbon (DOC) concentration decreases monotonically with depth.

Although the sampling time period was very short, relevant preliminary conclusions can be drawn. Phytoplankton blooms form in spring and summer in the southwestern Ross Sea. Their temporal phasing depends on the phytoplankton species composition, hydrographical conditions and sea-ice dynamics. The largest blooms are dominated by Phaeocystis Antartica; this bloom is the first to develop, beginning in late October or early November, at a time when sea-ice is still abundant in the region. This bloom is also the first to end, generally exhibiting signs of decline as early as mid-December. The second type of bloom develops later in the year, beginning in December and January, in association with the highly stratified surface waters and is dominated by diatoms. ${ }^{25,26}$ Usually the two blooms are partially superimposed, with a single peak of primary production in December-January, but in some seasons dual phytoplankton blooms were observed; e.g. in December 1997 and January 1998 well defined chlorophyll maxima and primary production were registered in the Ross Sea area. ${ }^{26}$

The data here reported show two sharp HCHO maximum values at $25-30 \mathrm{~m}$ depth, in November and January, which correspond to the phytoplankton blooms occurring in the Ross Sea areas. This links formaldehyde formation to the phytoplanktonic activity, supporting the suggestion that marine areas with high biogenic production may constitute a source of $\mathrm{HCHO}$ to the atmosphere.

\section{Conclusion}

A fluorimetric method for the determination of $\mathrm{HCHO}$ has been improved for application to seawater samples. The approach is simple, convenient, rapid and accurate.

The interference from low molecular weight aldehydes and other organic compounds was found to be negligible. The method has a very high linearity from concentrations of a few $\mu \mathrm{g} \mathrm{L}^{-1}$ to about $1000 \mu \mathrm{g} \mathrm{l}^{-1}$, and a good reproducibility $(2 \%)$ even at low concentrations. The detection limit of $0.7 \mu \mathrm{g}$ $\mathrm{L}^{-1}$ is sufficient to determine the formaldehyde content of seawater samples.

Analysis of microlayer and sub-surface seawater samples (from Ross Sea, Antarctica) using this method did not show enrichment in the microlayer, probably because of the short $\mathrm{HCHO}$ residence time in the microlayer.

The formaldehyde concentration/depth profiles in the water column and temporal changes seem to support a link between $\mathrm{HCHO}$ formation and phytoplankton blooms, suggesting $\mathrm{HCHO}$ as a marker of the marine biogenic activity.

More measurements related to late summer and periods characterised by low phytoplanktonic activity, are necessary in order to improve our knowledge of the mechanisms involved in formaldehyde production and transport processes through the water column.

\section{Acknowledgements}

This research was carried out within the framework of Projects on Chemical Contamination of the PNRA (Italian National
Program for Antarctic Research) and was financially supported through a co-operation agreement with the Venice University. The authors wish to thank all the participants to the XIV and XVII Antarctic Expeditions as well as the captain and the crew of the IceBjorn for their valuable help.

\section{References}

1 P. Carlier, H. Hannachi and G. Mouvier, Atmos. Environ., 1986, 20, 2079.

2 J. G. Goode, R. J. Yokelson, D. E. Ward, R. A. Susott, R. E. Babbitt, M. A. Davies and W. M. Hao, J. Geophys. Res., 2000, 105(D17), 22147.

3 H. Sakugawa and I. R. Kaplan, Atmos. Environ., Part A, 1993, 27A(9), 1509.

4 P. Khare, G. S. Satsangi, N. Kumar, M. K. Kumari and S. S. Srivastava, Atmos. Environ., 1997, 31, 3867.

5 L. M. Cardenas, G. Mills and S. A. Penkett, in Tropospheric Measurements of Formaldehyde, Proceedings of EUROTRAC Symposium '98, ed. P. M. Borrell and P. Borrell, 1999, p. 356.

6 K. Lochte, W. Broadgate and E. Urban, Global Change Newsletter, 2003, 56, 19.

7 K. Mopper and W. L Stahovec, Mar. Chem., 1986, 19(4), 305.

8 X. Zhou and K. Mopper, Mar. Chem., 1997, 56, 201.

9 P. S. Liss, in Chemistry of the Sea Surface Microlayer, Chemical Oceanography, ed. J. P. Riley and G. Skirrow, Academic Press, London, 1975, p. 193.

10 M. Caccia, R. Bono, Ga. Bruzzone, Gi. Bruzzone, E. Spirandelli, G. Veruggio and A. M. Stortini, Technical Report Rob-SESAMO03-01, 2003.

11 G. R. DiTullio and W. O. Smith, Jr., Deep-Sea Res. I, 1995, 42(6), 873.

12 W. D. Gardner, M. J. Richardson and W. O. Smith, Jr., Deep-Sea Res. II, 2000, 47, 3423.

13 W. O. Smith, Jr., Antarct. J. U. S., 1995, 30, 195.

14 O. Largiuni, R. Udisti, R. Traversi and G. Piccardi, Int. J. Environ. Anal. Chem., 2002, 82(2), 97.

15 A. Cincinelli, A. M. Stortini, M. Perugini, L. Checchini and L. Lepri, Mar. Chem., 2001, 76(1-2), 77.

16 A. M. Stortini, C. Turetta, F. Corami, L. Manodori, S. Ferrari and G. Capodaglio, The Microlayer's Role in the Transport of Micropollutants in the Venice Lagoon. Scientific Research and Safeguarding of Venice, CORILA Research, Program 2001, Results, ed. P. P. Campostrini, (C) Istituto Veneto di Scienze, Lettere ed Arti-Venezia e CORILA-Venezia, 2002, p. 459.

17 G. W. Harvey, Limnol. Oceanogr., 1966, 11, 608.

18 V. Wagner, R. von Glasow, H. Fischer and P. J. Crutzen, J. Geophys. Res., 2002, 107(D3), ACH 3-1.

19 M. A. Eberhardt and J. McN. Sieburth, Mar. Chem., 1985, 17(3), 199.

20 C. Economou and N. Mihalopoulos, Atmos. Environ., 2002, 36, 1337.

21 P. G. Desideri, L. Lepri and L. Checchini, Ann. Chim. (Rome), 1991, 81, 395.

22 P. G. Desideri, L. Lepri, L. Checchini, D. Santianni, F. Masi and M. Bao, Int. J. Environ. Anal. Chem., 1995, 61, 319.

23 P. S. Liss and P. G. Slater, Nature, 1974, 247, 181.

24 M. D. Doval, X. A. Álvarez-Salgado, C. G. Castro and F. F. Pérez, Deep-Sea Res. II, 2002, 49, 663.

25 K. R. Arrigo, G. R. DiTullio, R. B. Dunbar, M. P. Lizotte, D. H. Robinson, M. Van Woert and D. L. Worthen, J. Geophys. Res., 2000, 105, 8827.

26 K. R. Arrigo and G. L. van Dijken, Deep-Sea Res. II, 2004, 51, 117. 